\title{
Intercalation, decomposition, entrapment - a new route to graphene nanobubbles
}

DOI:

10.1039/D0CP00592D

Document Version

Accepted author manuscript

Link to publication record in Manchester Research Explorer

\section{Citation for published version (APA):}

Zahra, K. M., Byrne, C., Alieva, A., Casiraghi, C., \& Walton, A. (2020). Intercalation, decomposition, entrapment a new route to graphene nanobubbles. Physical Chemistry Chemical Physics.

https://doi.org/10.1039/D0CP00592D

\section{Published in:}

Physical Chemistry Chemical Physics

\section{Citing this paper}

Please note that where the full-text provided on Manchester Research Explorer is the Author Accepted Manuscript or Proof version this may differ from the final Published version. If citing, it is advised that you check and use the publisher's definitive version.

\section{General rights}

Copyright and moral rights for the publications made accessible in the Research Explorer are retained by the authors and/or other copyright owners and it is a condition of accessing publications that users recognise and abide by the legal requirements associated with these rights.

\section{Takedown policy}

If you believe that this document breaches copyright please refer to the University of Manchester's Takedown Procedures [http://man.ac.uk/04Y6Bo] or contact uml.scholarlycommunications@manchester.ac.uk providing relevant details, so we can investigate your claim.

\section{OPEN ACCESS}




\title{
Intercalation, decomposition, entrapment - a new route to graphene nanobubbles.
}

Received 00th January 20xx, Accepted 00th January 20xx

DOI: $10.1039 / x 0 x \times 00000 x$

\begin{abstract}
Khadisha M. Zahra ${ }^{a b}$, Conor Byrne ${ }^{a b}$, Adriana Alieva ${ }^{a}$, Cinzia Casiraghi ${ }^{a}$, Alex S. Walton ${ }^{* a b}$
Graphene Nanobubbles (GNBs) have become the subject of recent research due to their novel physical properties. However present methods to create them involve either extreme conditions or complex sample fabrication. We present a novel approach which relies on the intercalation of small molecules $\left(\mathrm{NH}_{3}\right)$, their surface-mediated decomposition and the formation of larger molecules $\left(\mathrm{N}_{2}\right)$ which are then entrapped beneath the graphene in bubbles. Our hypothesised reaction mechanism requires the copper substrate, on which our graphene is grown via chemical vapour deposition (CVD), be oxidised before the reaction can occur. This was confirmed through x-ray photoelectron spectroscopy (XPS) data of both oxidised and reduced $\mathrm{Cu}$ substrate samples. The GNBs have been analysed through atomic force microscopy (AFM, after $\mathrm{NH}_{3}$ treatment) and XPS, which reveals the formation of five distinct $\mathrm{N}$ 1s peaks, attributed to $\mathrm{N}_{2}$ entrapment, $\mathrm{N}$ doping species and atomic nitrogen bonded with the $\mathrm{Cu}$ within the substrate. This method is simple, occurs at low temperatures $(520 \mathrm{~K})$ and integrates very easily with conventional CVD graphene growth, so presents an opportunity to open up this field of research further.
\end{abstract}

\section{Introduction}

Graphene nanobubbles (GNBs) are a phenomenon which arise due to graphene's unique combination of strength, elasticity and gas impermeability ${ }^{1-3}$. This allows the entrapment of gas molecules in small, highly pressurised mesoscale bubbles. Pressures within these bubbles have been reported to be in the order of $\mathrm{MPa}{ }^{4-7}$, with one report achieving up to $1 \mathrm{GPa}{ }^{8}$. The small volumes of gas contained within GNBs are therefore a route to study gas-phase reactions in small volumes or under high pressures, potentially producing new exotic phases of matter ${ }^{9}$.

GNBs, and larger micro-scale bubbles, are regularly found between the graphene and silicon-oxide substrate, believed to have formed due to the trapping of air upon the transfer of mechanically exfoliated graphene flakes onto the flat substrate ${ }^{10,11}$. In case of chemical vapour deposition (CVD), where transfer is used, bubbles are usually formed due to polymeric residual or contaminates ${ }^{12}$. This characteristic has been utilised to directly measure graphene's adhesion to $S$ surfaces by intercalating gold nanoparticles underneath these 'blisters' ${ }^{13}$, and to study graphene under biaxial strain ${ }^{14}$ Accompanying theoretical studies have been made to establish the mechanical properties ${ }^{4}$ and numerical methods to describe the curvature of GNBs 5 .

\footnotetext{
a. Department of Chemistry, The University of Manchester, Manchester M13 9PL, UK.

b. Photon Science Institute, The University of Manchester, Manchester M13 9PL, UK. Electronic Supplementary Information (ESI) available: [The ESI includes details and figures on; the life span of $\mathrm{N}_{2}$ bubbles, raw Raman data at each stage of treatmen and details of the background subtractions and Raman analysis of the graphene on $\mathrm{Cu}$.].

See DOI: $10.1039 / \mathrm{x} 0 \times x \times 0000 x$
}

These bubbles are of great interest for both fundamental science and technological applications. The high levels of strain in the GNBs have also been demonstrated to give rise to exotic physics such as strain-induced pseudo-magnetic fields of $>300 \mathrm{~T}^{15}$ and non-linear optical behaviour ${ }^{16}$. Furthermore, the production of GNBs has been demonstrated to facilitate lift-off and transfer of CVD graphene 17,18 and has been proposed as a mechanism for gas storage 10,19 .

Thus far, GNBs have been produced by either electrolysis 17-19, extreme conditions such as intense laser irradiation ${ }^{16}$, or by complex sample fabrication such as lithography ${ }^{14,20}$. In this paper we report a new route for the formation of GNBs based upon the intercalation of small molecules under the graphene, their substrate-mediated decomposition, forming larger molecules which are then entrapped by the graphene, creating GNBs. This process is simple, occurs at low temperatures and is easily integrated into the conventional CVD process.

Specifically, we describe the intercalation of $\mathrm{N}_{2}$ and formation of $\mathrm{N}_{2}$ GNBs beneath CVD monolayer graphene on $\mathrm{Cu}$ substrates via annealing in $\mathrm{NH}_{3}$ gas. We show that the reaction is governed by the presence of a $\mathrm{Cu}$ oxide layer on the substrate. A recent study by Zhao et al. ${ }^{21}$ attempted to decouple graphene from its substrate via the intercalation of $\mathrm{N}$ atoms through thermal treatments with $\mathrm{N}_{2}$ gas. Their endeavour to intercalate $\mathrm{N}$ was chosen as, unlike the intercalation of other atoms, $\mathrm{N}$ atoms provide the possibility of achieving graphene charge neutrality. This would allow the same high electron mobilities that are associated with freestanding graphene, as shown using first principles density functional calculations by Caffrey et al. ${ }^{22}$. The attempt by Zhao et al. was unsuccessful in the pressure range $1.3 \times 10^{-6}-0.1$ mbar and temperature range of room temperature (RT) $-350{ }^{\circ} \mathrm{C}$ on both $\operatorname{Ir}(111)$ and $\mathrm{Ni}(111)$.

We have chosen $\mathrm{NH}_{3}$ gas, as Wang et al. ${ }^{23}$ were able to achieve $\mathrm{N}$-intercalation and $\mathrm{N}$-doping through thermal treatments of 
epitaxial graphene on $\mathrm{SiC}$ with $\mathrm{NH}_{3}$. Their results indicate that the $\mathrm{NH}_{3}$ dissociates during the thermal reaction $(25 \mathrm{ml} / \mathrm{min}$ at $500{ }^{\circ} \mathrm{C}$ ), leaving $\mathrm{N}$ atoms at the surface. Similarly to Wang et al., simultaneous $\mathrm{N}$-doping of the graphene also occurs during the treatment shown in this paper. Samples have been analysed using X-ray photoelectron spectroscopy (XPS), Raman and atomic force microscopy (AFM). Raman spectra at each stage of the treatment indicate that the graphene remains intact and of high quality throughout.

\section{Results and discussion}

In our work CVD graphene on $\mathrm{Cu}$ substrate samples were annealed in $\mathrm{NH}_{3}$ to a sample temperature of $600 \mathrm{~K}$ and a pressure of $0.6 \mathrm{mbar}$, which was maintained for 20 mins. It was then cooled to $400 \mathrm{~K}$ before removing the $\mathrm{NH}_{3}$. After $\mathrm{NH}_{3}$ treatment, XPS was carried out with no air exposure to the samples. Distinct $\mathrm{N}$ 1s peaks appear after the $\mathrm{NH}_{3}$ treatment (Figure 1). In the first region a peak appears at $404.9 \mathrm{eV}\left(\mathrm{N}_{\mathrm{A} 1}\right)$ and has a lower binding energy $\left(E_{B}\right)$ shoulder feature at $403.4 \mathrm{eV}$ $\left(N_{A 2}\right)$. These peaks also persist after prolonged exposure to atmospheric conditions (Electronic Supplementary Information, ESI, Figure $S 1$ ). $N_{A 1,2}$ are too high $E_{B}$ for any feasible surface bound $\mathrm{N}$ species, due to the reducing conditions of heating in $\mathrm{NH}_{3}$. Vapour reference peaks were collected for both $\mathrm{NH}_{3}$ and air $\left(\mathrm{N}_{2}\right)$. These were positioned at $401.6 \mathrm{eV}$ and $405.8 \mathrm{eV}$,

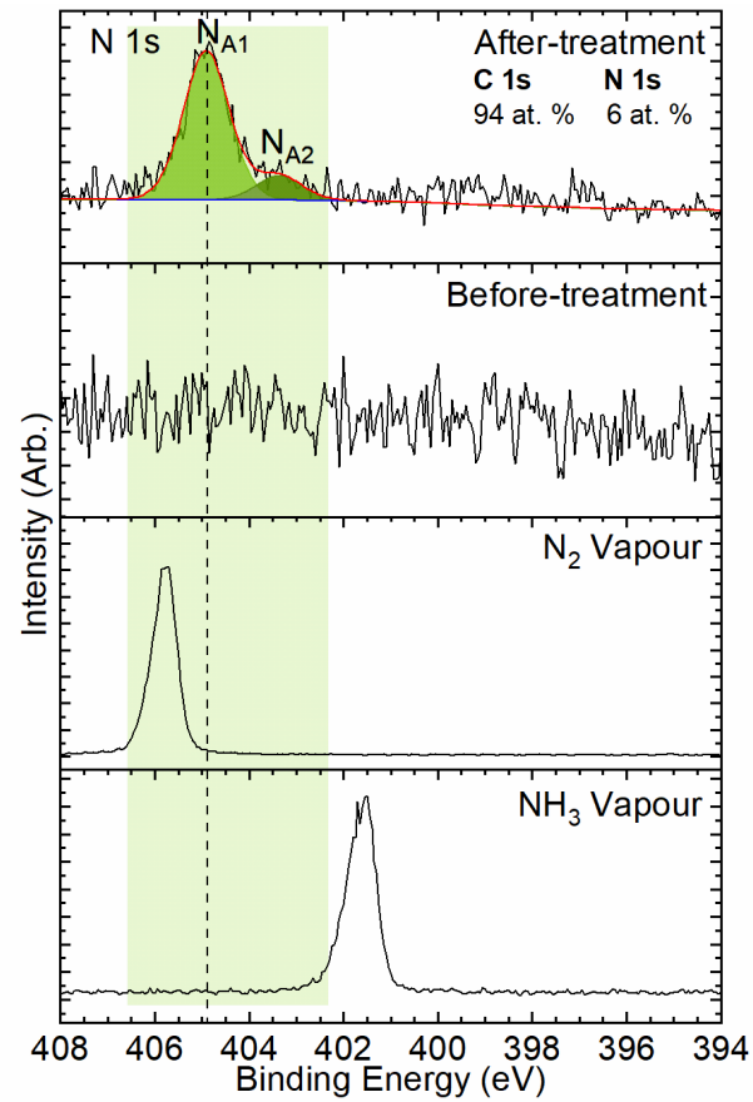

Figure 1. XPS data. A comparison of the $\mathrm{N}$ 1s peaks after $\mathrm{NH}_{3}$ treatment $\left(\mathrm{N}_{\mathrm{A1}, 2}\right)$ in reference to $\mathrm{N}_{2}(405.8 \mathrm{eV})$ and $\mathrm{NH}_{3}(401.6 \mathrm{eV})$ vapour peaks. No $\mathrm{N}$ 1s peaks are present before $\mathrm{NH}_{3}$ treatment. respectively. Neither reference peak corresponded directly with $\mathrm{N}_{\mathrm{A} 1,2}$, though only a minor shift of $\sim 1 \mathrm{eV}$ can be seen between the $N_{A 1,2}$ peaks and the $N_{2}$ vapour peak. The same $N$ 1s region before $\mathrm{NH}_{3}$ treatment, shows no apparent peaks. Numerous reports have been made assigning an $\mathrm{N} 1 \mathrm{~s}$ peak at $\sim 404-405 \mathrm{eV}$ to $\mathrm{N}_{2}$ intercalated within multilayer-carbon nanotubes (MLCNT) or captured inside the cavity ${ }^{24-27}$. A study by Tillborg et al. ${ }^{28}$, demonstrated the effect the substrate has on reducing the molecular nitrogen $\mathrm{E}_{\mathrm{B}}$. Using XPS they observed a screening effect through the physisorption of $\mathrm{N}_{2}$ on highly oriented pyrolytic graphite (HOPG) at $25 \mathrm{~K}$, lowering the $E_{B}$ by up to 1.4 $\mathrm{eV}$ compared to free molecules. This shift in $\mathrm{E}_{\mathrm{B}}$ would account for the difference in $\mathrm{N}_{\mathrm{A} 1,2}$ and the $\mathrm{N}_{2}$ vapour peak. Examining the $\mathrm{C} 1 \mathrm{~s}$ shows a peak shift to lower $\mathrm{E}_{\mathrm{B}}$ after $\mathrm{NH}_{3}$ treatment (Figure 2), this indicates an electronic decoupling of the graphene from the substrate ${ }^{29}$, which would also suggest intercalation between the graphene and $\mathrm{Cu}$. Therefore, we propose that the $\mathrm{NH}_{3}$ intercalates at the graphene/Cu interface, reacts with the $\mathrm{Cu}$ substrate and forms $\mathrm{N}_{2}$. Hence, the $\mathrm{N}_{\mathrm{A} 1,2}$ peaks are ascribed to $N_{2}$ intercalated between the graphene and $\mathrm{Cu}$ in two different environments.

In order to establish the onset temperature of $\mathrm{N}_{2}$ intercalation, a near-ambient pressure (NAP) XPS experiment was performed where the XPS spectra were taken in-situ during the heating of a pristine graphene sample in an $\mathrm{NH}_{3}$ environment. The sample temperature was increased, by incrementing the e-beam heater, to a maximum of $600 \mathrm{~K}$. The $\mathrm{N}_{\mathrm{A} 1,2}$ peaks begin to appear above a sample temperature of $520 \mathrm{~K}$ (Figure 3a). A peak at $\sim 401.2 \mathrm{eV}$ in the N 1s (Figure 3a) can be seen throughout the temperature profile and is due to the $\mathrm{NH}_{3}$ vapour above the sample. Two other regions also become apparent. The second region has a peak at $398.4 \mathrm{eV}\left(\mathrm{N}_{\mathrm{B} 2}\right)$ and the third has a single peak at $396.5 \mathrm{eV}\left(\mathrm{N}_{\mathrm{C}}\right) . \mathrm{N}_{\mathrm{B} 2}$ is associated with nitrogen doping of

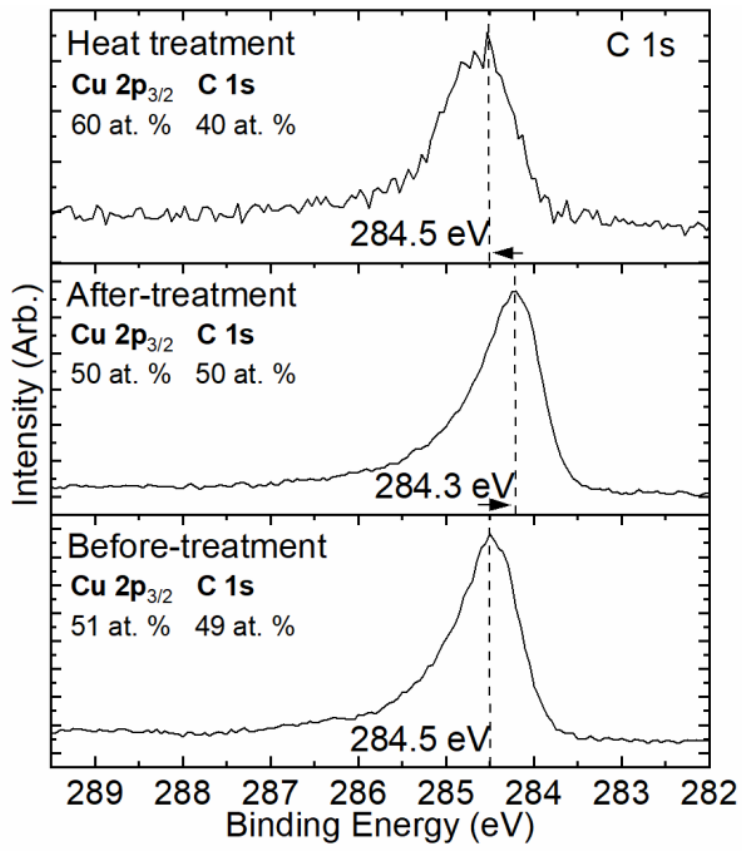

Figure 2. XPS data collected from CVD graphene samples. A C 1s comparison shows a shift to lower binding energy after $\mathrm{NH}_{3}$ treatment and back to $284.5 \mathrm{eV}$ upon release of the $\mathrm{N}_{2}$ after UHV heating 

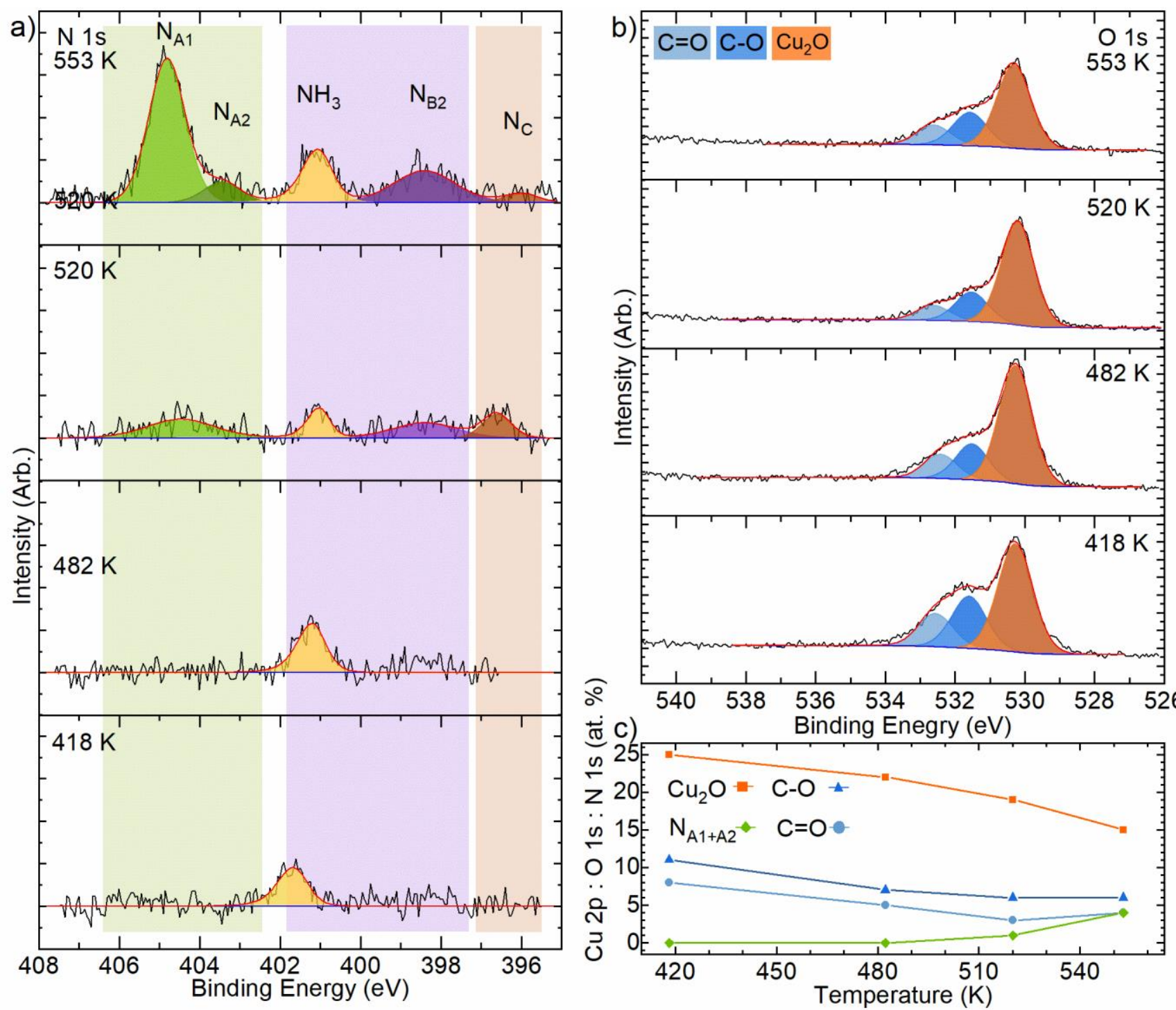

Figure 3(a-b). In-situ XPS data collected of graphene during an $\mathrm{NH}_{3}$ treatment. (a) The $\mathrm{N} 1 \mathrm{~s}$ spectra shows the $\mathrm{N}_{\mathrm{A} 1,2}$ peaks (403-405 eV) begin to appear at $520 \mathrm{~K}$. (b) The overall intensity of the $\mathrm{O} 1 \mathrm{~s}$ is shown to decrease as a function of increasing temperature. (c) This is also shown in the atomic concentration (at. \%) of the individual $\mathrm{O} 1 \mathrm{~s}$ components $\left(\mathrm{Cu}_{2} \mathrm{O}\right.$, $\mathrm{C}=\mathrm{O}, \mathrm{C}-\mathrm{O}$ ) as a comparison to the $\mathrm{Cu} 2 \mathrm{p}_{3 / 2}$, with a corresponding increase in $\mathrm{N}_{\mathrm{A} 1+\mathrm{A} 2}$ from $520 \mathrm{~K}$.

graphene (specifically pyridinic doping ${ }^{30}$ ), whereas $N_{C}$ is attributed to either low levels of atomic nitrogen bonded with the $\mathrm{Cu}$ within the substrate ${ }^{31-33}$, or chemisorbed nitrogen at $\mathrm{Cu}$ atoms formed by dissociation of $\mathrm{N}_{2}{ }^{34}$. We expect that the majority of $\mathrm{NH}_{3}$ intercalated between the graphene/Cu interface during treatment would react with the substrate and decompose. Though trace amounts of $\mathrm{NH}_{3}$ may remain after treatment, this would be convoluted within an $\mathrm{N}_{\mathrm{B} 1}$ peak ( $\sim 400.5 \mathrm{eV})$ which is also associated with nitrogen doping (graphitic ${ }^{30}$ ). A study by Sueyoshi et al. ${ }^{35}$ on the coadsorption of $\mathrm{NO}$ and $\mathrm{NH}_{3}$ on $\mathrm{Cu}(111)$, demonstrates the desorption of $\mathrm{NH}_{3}$ at $300 \mathrm{~K}$. This also suggests that it would not remain adsorbed to the $\mathrm{Cu}$ surface in our temperature range, as upon cooling after the treatment $\mathrm{NH}_{3}$ is removed at $400 \mathrm{~K}$. Therefore the assignment of the $\mathrm{NH}_{3}$ vapour peak has not been made in after $\mathrm{NH}_{3}$ treated samples.

Similarly, XPS spectra of a $\mathrm{NH}_{3}$ treated sample were also taken in-situ whilst annealing in vacuum. The sample was annealed over $\sim 5.5$ hours up to a sample temperature of $625 \mathrm{~K} . \mathrm{N}_{\mathrm{A} 1,2}$ and
$\mathrm{N}_{\mathrm{C}}$ begin to diminish above $520 \mathrm{~K}$ (Figure 4a). The $\mathrm{N}_{\mathrm{C}}$ peak is absent above $535 \mathrm{~K}$, whilst the $\mathrm{N}_{\mathrm{A} 1,2}$ peaks decreases gradually up to $595 \mathrm{~K}$. This decrease is accompanied by a shift in $\mathrm{C} 1 \mathrm{~s}$ peak to higher $E_{B}$ (Figure $4 b$ ). The last $C$ 1s scan of the colour map is plotted in Figure 2 and shows the $\mathrm{sp}^{2}$ peak returns to $284.5 \mathrm{eV}$, as expected upon the release of $\mathrm{N}_{2}$.

Analysis of the $\mathrm{O} 1 \mathrm{~s}$ peaks before and after $\mathrm{NH}_{3}$ treatment reveals a reduction in overall atomic percentage (at. \%), compared with the $\mathrm{Cu} 2 \mathrm{p}_{3 / 2}$. This was also seen in the temperature profile of the in-situ $\mathrm{NH}_{3}$ treatment, where the $\mathrm{O} 1 \mathrm{~s}$ components $\mathrm{C}-\mathrm{O}(\sim 531.6 \mathrm{eV}), \mathrm{C}=\mathrm{O}(\sim 532.6 \mathrm{eV})$ and $\mathrm{Cu}_{2} \mathrm{O}\left(\sim 530.3 \mathrm{eV}{ }^{36}\right)$ at. \% are inversely proportional to the temperature (Figure $3 \mathrm{~b}-\mathrm{c}$ ). This suggests that the intercalation is associated with a reduction mechanism and requires the underlying $\mathrm{Cu}$ substrate to be oxidised in order to initiate the reaction.

A common reduction reaction is that of heated copper (II) oxide (CuO) and $\mathrm{NH}_{3}$, forming $\mathrm{N}_{2}$ and water ${ }^{37}$ :

$$
2 \mathrm{NH}_{3}+3 \mathrm{CuO} \rightarrow \mathrm{N}_{2}+3 \mathrm{Cu}+3 \mathrm{H}_{2} \mathrm{O}
$$



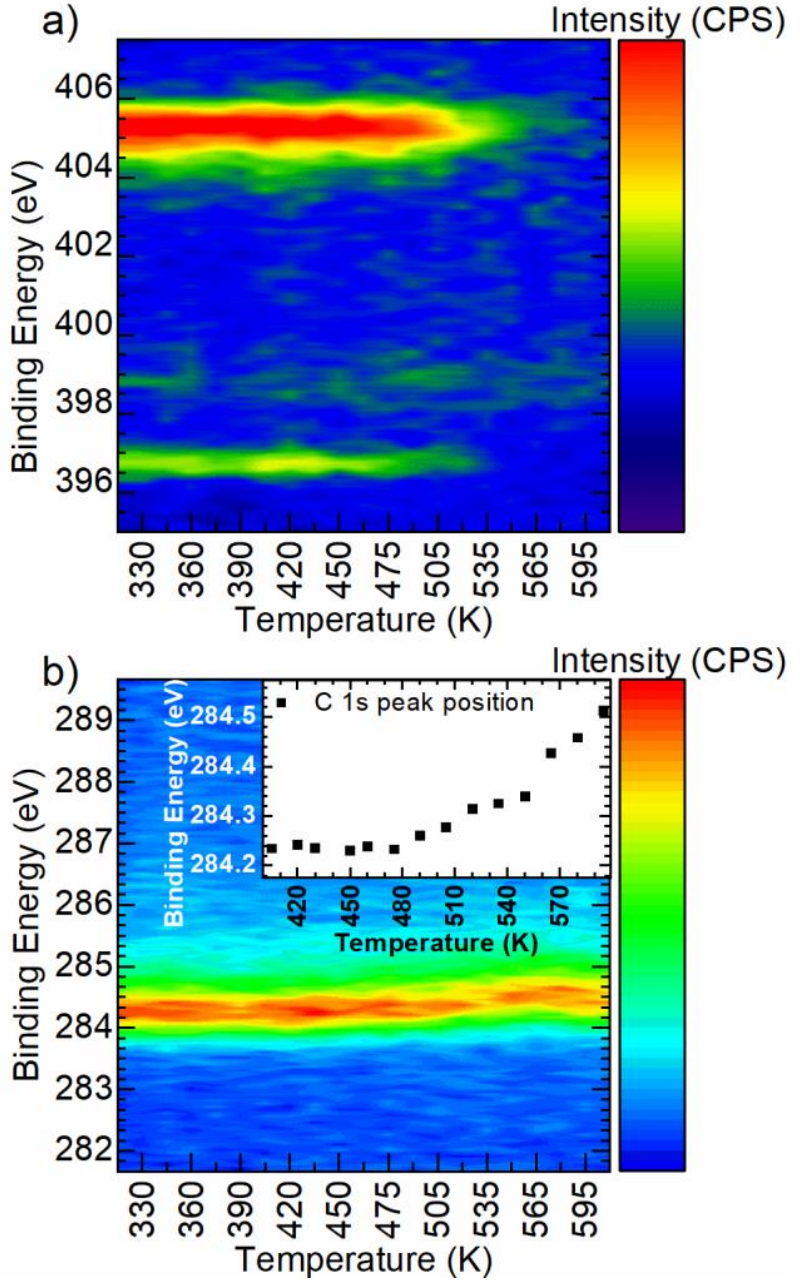

Figure 4. In-situ XPS data collected from a graphene sample heated in vacuum after $\mathrm{NH}_{3}$ treatment. (a) Colour map tracks the change in $\mathrm{N} 1 \mathrm{~s}$ peak intensity as a function of temperature. (b) Colour map indicates a shift in $\mathrm{C} 1 \mathrm{~s}$ peak position to higher binding energy with increasing temperature, also shown in the inset.
Under ambient conditions, $\mathrm{Cu}$ foil oxidises to copper (I) oxide $\left(\mathrm{Cu}_{2} \mathrm{O}\right)$ and therefore using Equation (1) we propose a similar reaction occurs for $\mathrm{Cu}_{2} \mathrm{O}$ :

$$
2 \mathrm{NH}_{3}+3 \mathrm{Cu}_{2} \mathrm{O} \rightarrow \mathrm{N}_{2}+6 \mathrm{Cu}+3 \mathrm{H}_{2} \mathrm{O}
$$

To test this hypothesis, an oxidised and a reduced sample were also simultaneously annealed in $\mathrm{NH}_{3}$. $\mathrm{NH}_{3}$ treatment shows a dramatic reduction in $\mathrm{O} 1 \mathrm{~s}$ intensity (Figure $5 \mathrm{~b}$ ) for the oxidised sample with very distinct $\mathrm{N}_{\mathrm{A} 1,2}, \mathrm{~N}_{\mathrm{B} 1,2}$ and $\mathrm{N}_{\mathrm{C}}$ peaks also observed (Figure 5c). Whereas the reduced sample shows no obvious change in the $\mathrm{O} 1 \mathrm{~s}$ peak and no discernible $\mathrm{N}$ 1s peaks.

This result further validates our proposed reaction, where $\mathrm{NH}_{3}$ intercalates at the graphene/Cu interface, reducing the oxidised $\mathrm{Cu}$ substrate and forming $\mathrm{N}_{2}$ and $\mathrm{H}_{2} \mathrm{O}$. Our XPS results show that $\mathrm{N}_{2}$ is trapped between the $\mathrm{Cu}$ and graphene, whereas we do not detect any entrapped water. A molecular $\mathrm{H}_{2} \mathrm{O}$ peak would occur at $\sim 534 \mathrm{eV}$ in the $\mathrm{O} 1 \mathrm{~s}$ signal ${ }^{38-40}$, which was never observed (see Figure $5 b$ ).

We propose two possible hypotheses for why $\mathrm{N}_{2}$ is trapped but $\mathrm{H}_{2} \mathrm{O}$ is not. The first argument is based upon the molecules' respective kinetic diameters. Several studies have investigated intercalating molecules between graphene and its underlying substrate ${ }^{41-43}$. Mu et al. ${ }^{43}$ and Graišnäs et al. ${ }^{41}$ both intercalate $\mathrm{CO}$ between graphene/Pt and graphene/Ir, respectively. The atomic distance between graphene/Pt is $3.30 \AA$ and graphene/Ir is $3.51 \AA$, which are both near to the kinetic diameter $\left(d_{k}\right)$ of $\mathrm{CO}(3.76 \AA)$. The intercalation is thought to take place through open channels at edge sites. Similarly the atomic distance between graphene and $\mathrm{Cu}$ is $2.24 \AA^{44}$ whilst $\mathrm{NH}_{3}$ has a $d_{k}=2.60 \AA{ }^{45} . \mathrm{H}_{2} \mathrm{O}$ has a $d_{k}=2.65 \AA 45$ however $\mathrm{N}_{2}$ is a far larger molecule $\left(d_{k}=3.64 \AA^{45}\right)$.

This suggests that the smaller $\mathrm{NH}_{3}$ molecules may react with the $\mathrm{Cu}$ oxide surface through open channels, whilst the larger $\mathrm{N}_{2}$ molecules get trapped at the graphene/Cu interface. The
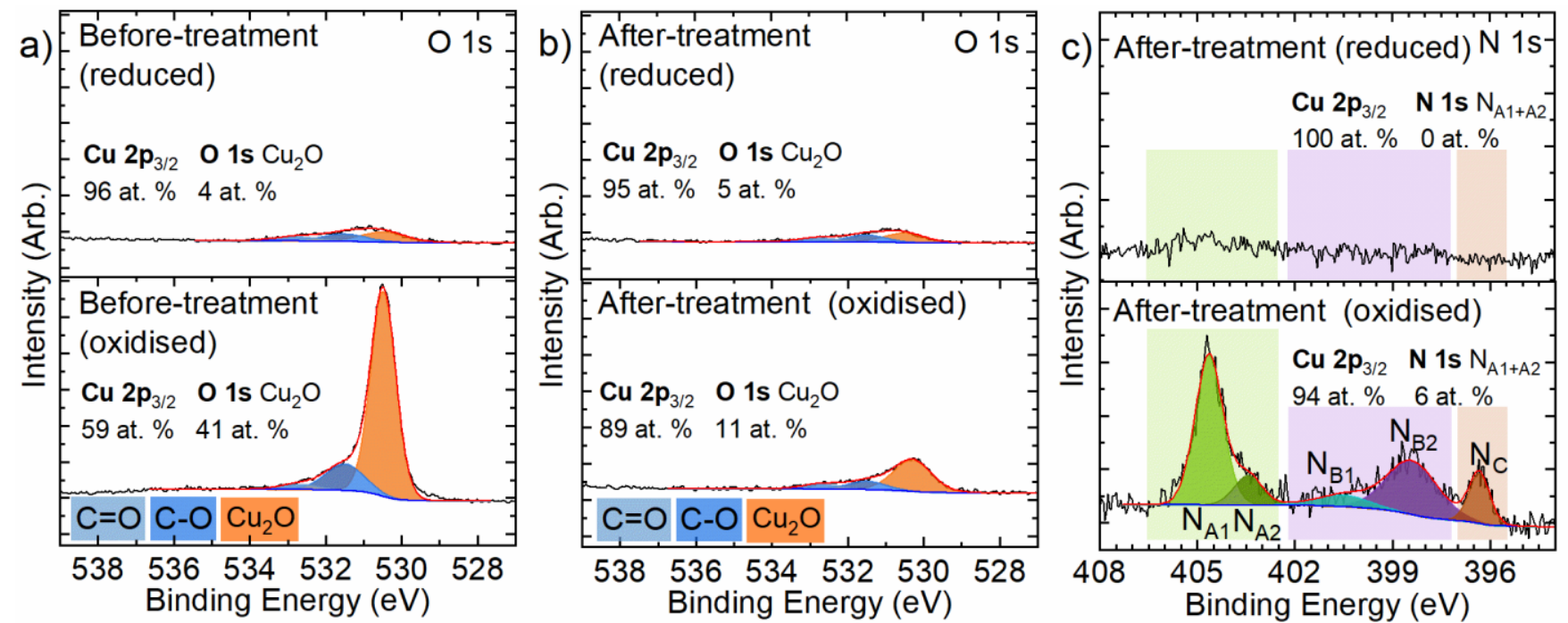

Figure 5. XPS data collected from CVD graphene samples. (a) A comparison of the $\mathrm{O}$ 1s peaks before $\mathrm{NH}_{3}$ treatment, of oxidised and reduced samples on Cu. (b) Data was also collected after $\mathrm{NH}_{3}$ treatment, where a significant reduction in intensity can be seen in the oxidised sample. (c) Examining the $\mathrm{N} 1 \mathrm{~s}$ peak shows five distinct peaks associated with; $\mathrm{N}_{2}\left(\mathrm{~N}_{\mathrm{A} 1,2}\right)$, nitrogen doping $\left(\mathrm{N}_{\mathrm{B} 1,2}\right)$ and $\mathrm{N}$ bonded to $\mathrm{Cu}\left(\mathrm{N}_{\mathrm{C}}\right)$ in the oxidised sample but no defined peaks appear in the reduced sample after $\mathrm{NH}_{3}$ treatment providing further validation for the Cu oxide reaction mechanism. 

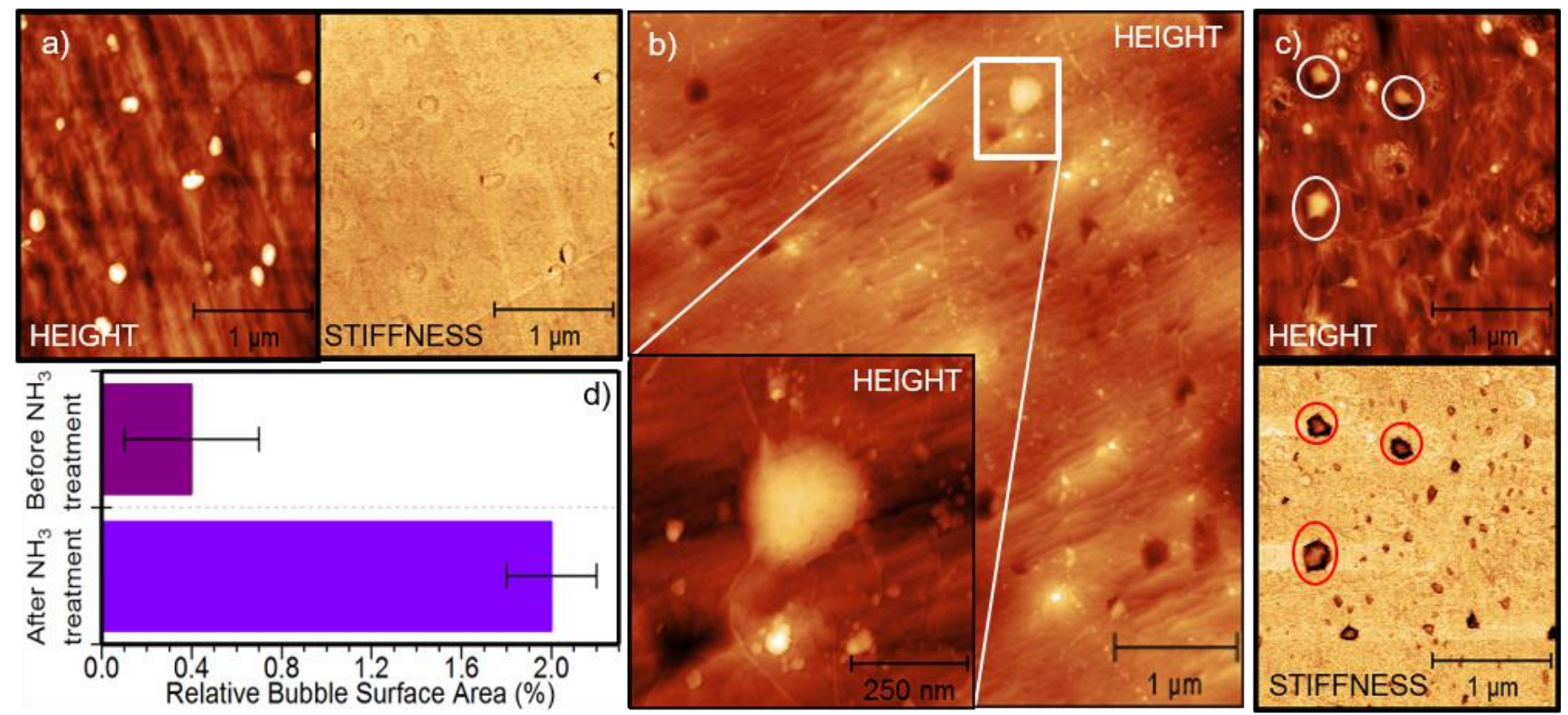

Figure 6(a-c). AFM data collected before and after $\mathrm{NH}_{3}$ treatment of CVD graphene. (a) AFM image of the height (left) and stiffness (right) of a sample before treatment. (b) A pressurised bubble feature can be seen in the height of an $\mathrm{NH}_{3}$ treated sample, with an inset at higher magnification. (c) Additional bubbles can be seen highlighted in white in the height (top) and red in the stiffness (bottom) of the $\mathrm{NH}_{3}$ treated samples. (d) Comparisons of the bubble distribution before and after $\mathrm{NH}_{3}$ treatment shows that there is a statistically significant increase in bubble coverage after $\mathrm{NH}_{3}$ anneals. These $\mathrm{GNBs}$ are attributed to $\mathrm{N}_{2}$ entrapment.

second hypothesis is based upon chemical reactivity - water is a comparatively reactive molecule and molecular nitrogen is highly inert. $\mathrm{H}_{2} \mathrm{O}$ is known to dissociate at edge sites ${ }^{46}$, with reports that the graphene edge sites may in fact reduce the activation energy for $\mathrm{H}_{2} \mathrm{O}$ dissociation, compared to bare $\mathrm{Cu}{ }^{47}$. It is possible that this decomposition is followed by hydroxyl diffusion across the surface, providing a route for $\mathrm{H}_{2} \mathrm{O}$ to escape. Research into porous graphene has also shown that $\mathrm{N}_{2}$ has one of the largest diffusion barriers $(1.75 \mathrm{eV}){ }^{48}$. Contrarily, $\mathrm{H}_{2} \mathrm{O}$ has a lower diffusion barrier $(1.44 \mathrm{eV})$ which is reduced further (to $0.94 \mathrm{eV}$ ) when three $\mathrm{C}-\mathrm{H}$ pairs, within the pore, are replaced with $\mathrm{N}$ atoms ${ }^{49}$. Therefore, another explanation for the absence of water may be due to the difference in chemical reactivity, where $\mathrm{H}_{2} \mathrm{O}$ dissociation occurs at graphene edges and subsequent recombinative desorption on areas of bare copper (recall the $\mathrm{NH}_{3}$ treatment is performed at $600 \mathrm{~K}$ - ) may provide a route for $\mathrm{H}_{2} \mathrm{O}$ to be "shuttled" out from underneath the graphene. No equivalent mechanism exists for the $\mathrm{N}_{2}$ as it is far too unreactive.

To assess changes in morphology after $\mathrm{NH}_{3}$ treatment, AFM data sets were recorded over $\sim 27$ different areas before treatment (Figure 6a) and after $\mathrm{NH}_{3}$ treatment (Figure 6b-c). Bright features can be seen in the height (Figure 6a, left) of the before $\mathrm{NH}_{3}$ treated sample which are thought to be contaminants present in the $\mathrm{Cu}$ substrate prior to growth as there also appears to be an absence of graphene in their surrounding area. The contaminants show no obvious difference to the rest of the sample in the stiffness (Figure 6a, right). Examining images of samples after $\mathrm{NH}_{3}$ treatment (Figure 6b-c) shows bubble like structures. The positive contrast in the height (Figure 6c, top), show these features (a selection of which have been highlighted a white circle for clarity) protrude above the surrounding area. Conversely, a negative

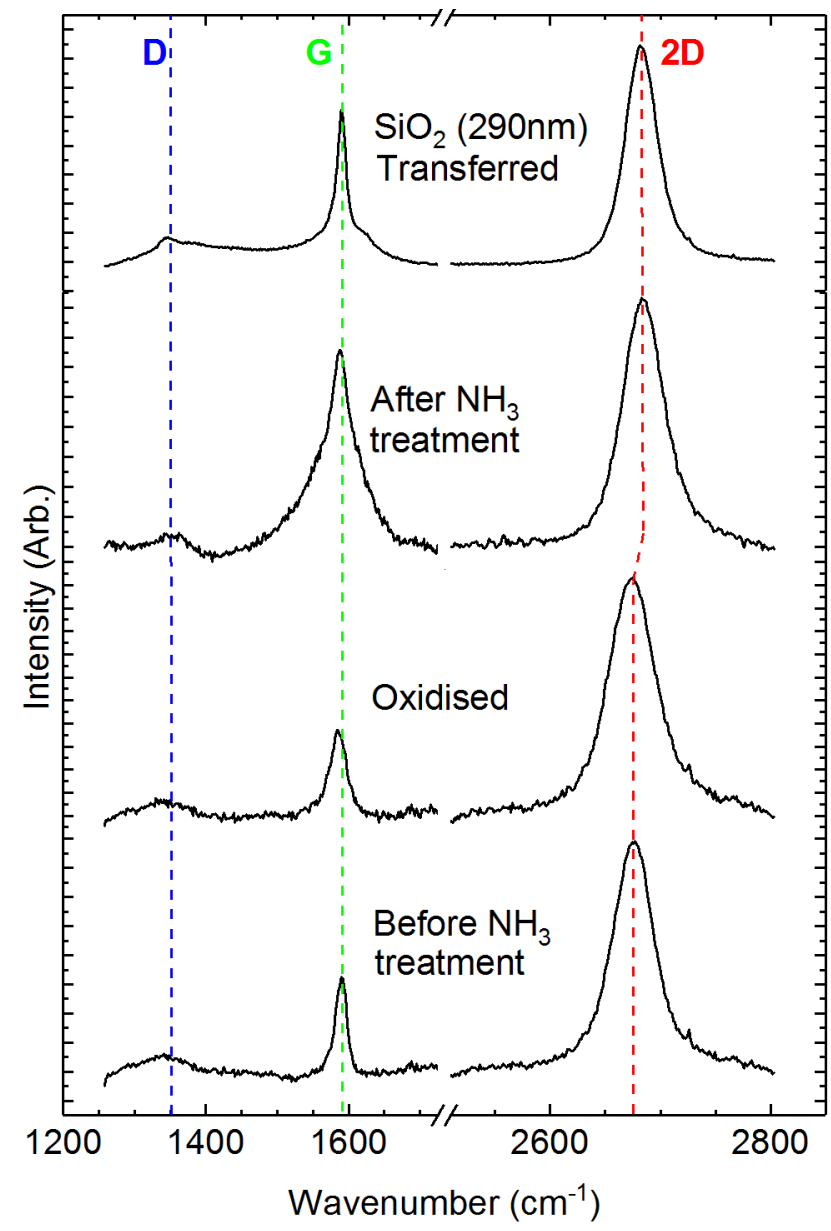

Figure 7. Raman data collected from CVD graphene samples. The appearance of the $G\left(\sim 1580 \mathrm{~cm}^{-1}\right)$ and $2 D\left(\sim 2700 \mathrm{~cm}^{-1}\right)$ peaks in each scan are characteristic to graphene. 

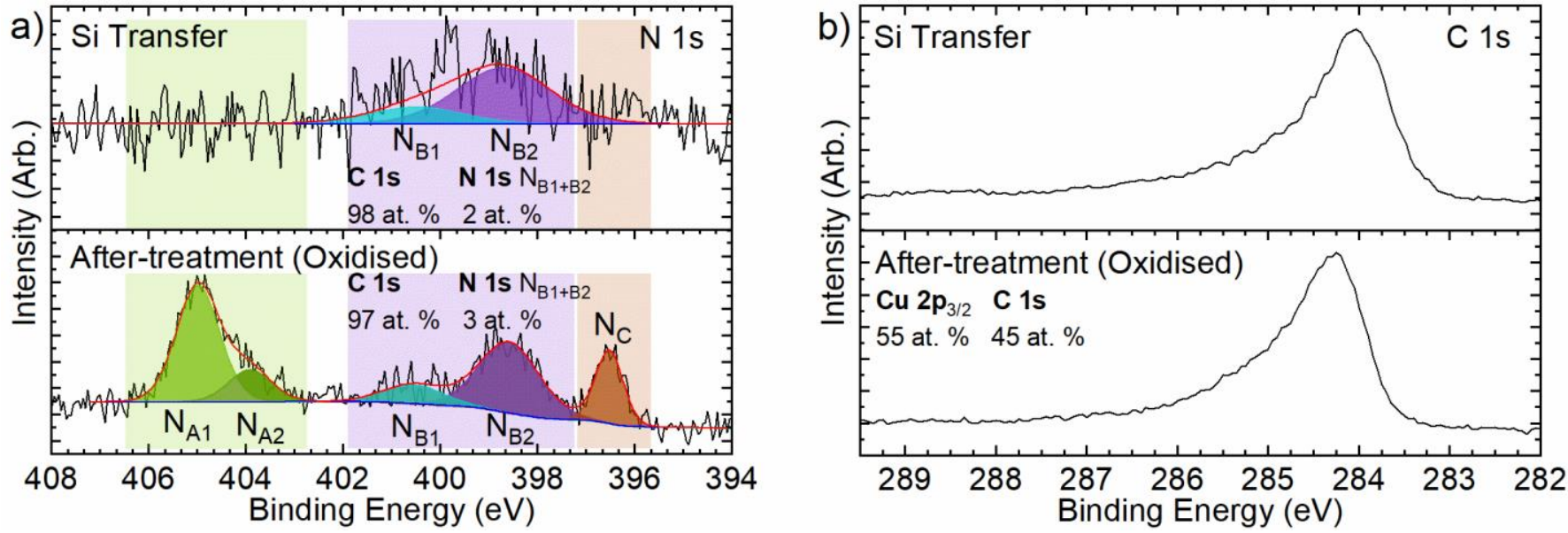

Figure 8. XPS data collected from CVD graphene samples. The graphene was transferred onto a Si wafer. (a) Examining the $N 1 s$ peak of the transferred graphene shows $\mathrm{N}_{\mathrm{A1}, 2}$ and $\mathrm{N}_{\mathrm{C}}$ are no longer present; however the $\mathrm{N}_{\mathrm{B} 1,2}$ peaks remains. (b) $\mathrm{C} 1 \mathrm{~s}$ remains asymmetric towards the high binding energy, indicating the graphene remains intact after transfer.

contrast is seen in the stiffness (Figure 6c, bottom, corresponding red circles) indicating these features are less stiff than the surrounding $\mathrm{Cu}$. Therefore we conclude that these features are in fact GNBs.

Though the appearance of GNBs may be seen prior to treatment $(0.4 \pm 0.3 \%)$, attributed to the intercalation of ambient atmosphere through defects which consequently accumulate in trenches of the $\mathrm{Cu}_{2} \mathrm{O}{ }^{50}$, a significantly higher distribution of bubbles are formed after $\mathrm{NH}_{3}$ treatment $(2.0 \pm$ $0.2 \%)$. This is estimated through statistical analysis of the relative surface coverage, by masking the GNBs in the stiffness data, shown in Figure $6 \mathrm{~d}$. Hence, the $\mathrm{N}_{2}$ entrapment is not simply distributed uniformly beneath the surface via intercalation, but appears to also be forming pressurised bubbles. This suggests that after $\mathrm{NH}_{3}$ treatment, there are two species of $\mathrm{N}_{2}$ coexisting; both a layer of intercalated $\mathrm{N}_{2}$ (evidenced by the $C 1$ s peak shifting, Figure 2 and Figure $4 \mathrm{~b}$ ) and GNBs (shown in the AFM, Figure $6 \mathrm{~b}-\mathrm{c}$ ). These inequivalent $\mathrm{N}_{2}$ environments give rise to two closely spaced peaks in the XPS, explaining the shoulder feature $\left(\mathrm{N}_{\mathrm{A} 2}\right)$ seen in the $\mathrm{N}_{2}$ entrapment peak of the $\mathrm{N}$ 1s spectra (Figure 2, 3a and $5 \mathrm{c}$ ).

Raman measurements were taken across the surface of each sample and then averaged. Details of the background subtraction are given in the experimental methods, with spectra before background subtraction shown in the ESI, Figure S2. A comparison of the Raman data collected at each experimental phase indicates that the graphene remains intact throughout the $\mathrm{NH}_{3}$ treatment and Si transfer (Figure 7). Analysis of the average $2 D: G$ intensity ratio $\left(\mathrm{I}_{2} \mathrm{D} / \mathrm{G}\right)$ indicate that the before $\mathrm{NH}_{3}$ treated sample is monolayer, with $\mathrm{I}_{2 \mathrm{D}} / \mathrm{I}_{\mathrm{G}}=2.4$. The $2 \mathrm{D}$ full width half maximum $\left(\mathrm{FWHM}_{2 \mathrm{D}}=43.0 \pm 0.4 \mathrm{~cm}^{-1}\right)$ is higher than that typically quoted for monolayer graphene, likely due to minor defect concentration in the graphene ${ }^{51}$. Prior to transfer, a constant broad peak can be seen in the region where the $D$ peak is expected $\left(\sim 1350 \mathrm{~cm}^{-1}\right)$, however this is an artefact of the photoluminescent background removal (see ESI). A D peak arising from defects in the graphene is a much sharper spectral feature, as seen in Figure 7 ( $\mathrm{Si}$ transfer). An increase in the FWHM of the $G$ peak is seen from before-treatment $\left(17.0 \pm 0.6 \mathrm{~cm}^{-1}\right)$ to after-treatment $\left(61 \pm 2 \mathrm{~cm}^{-1}\right)$. As the FWHM then decreases back to $19.7 \pm 0.9 \mathrm{~cm}^{-1}$ after Si transfer, this suggests that the broadening is due to the $\mathrm{N}_{2}$ entrapment, hence the FWHM decrease as the $\mathrm{N}_{2}$ is released during $\mathrm{Si}$ transfer. Various bubble shapes and sizes were identified in this experiment, with the largest GNBs in the order of 100's nm diameter, far smaller than the Raman spot size $(\sim 1.6 \mu \mathrm{m})$. Pressurising graphene to form bubbles (5-10 $\mu \mathrm{m}$ diameter) has previously been shown to cause a blue-shift in the spectra as a consequence of biaxial strain ${ }^{14}$. We hypothesis that the $G$ broadening could be due to an average over the surface (i.e. a distribution of bubble sizes and bubble-free areas).

Finally, an $\mathrm{NH}_{3}$ treated sample was transferred onto a Si wafer, using the wet polymer assisted transfer (PAT) process, described in the experimental methods. When examining the $\mathrm{N}$ 1s peak of the Si transferred sample, $\mathrm{N}_{\mathrm{A} 1,2}$ and $\mathrm{N}_{\mathrm{C}}$ are no longer discernible (Figure $8 \mathrm{a}$ ). $\mathrm{N}_{\mathrm{A} 1,2}$ and $\mathrm{N}_{\mathrm{C}}$ were expected to be absent as the process of the wet transfer would allow the $\mathrm{N}_{2}$ to escape and remove the $\mathrm{Cu}$ associated with the $\mathrm{N}_{\mathrm{C}}$ peak. As the $N_{B 1,2}$ peaks are attributed to nitrogen doping of the graphene they remain after the transfer. As shown by the distinctively asymmetric $C 1 \mathrm{~s} \mathrm{sp}{ }^{2}$ peak (Figure $8 \mathrm{~b}$ ) and the Raman spectrum (Figure 7) the graphene layer remains intact after transfer.

\section{Experimental}

Bluestone Global Tech (BGT) Materials Gratom-M-Cu-04 CVD graphene on $\mathrm{Cu}\left(25 \mu \mathrm{m}\right.$ thickness) and cut into $\sim 10 \times 10 \mathrm{~mm}^{2}$ samples were used throughout. Monolayer coverage specified by the manufacturer is $>95 \%$. The graphene was not transferred prior to $\mathrm{NH}_{3}$ treatments, and the bubbles were produced on the same $\mathrm{Cu}$ foil used during the CVD growth. XPS measurements were performed using a SPECS NAP-XPS instrument. The system consists of two ultra-high vacuum (UHV) chambers (preparation and analysis), and a PHOIBOS 150 NAP Analyser. A NAP cell is docked onto the analyser and the pressure inside it may then be brought up to the mbar range Photoelectrons were excited using monochromatic Al K $\mathrm{K}_{\alpha}$ radiation (1486.6 eV). A large spot size of $\sim 1 \mathrm{~mm}$ was used when 
scanning in standard UHV conditions, whilst a smaller spot size of $\sim 300 \mu \mathrm{m}$ was used for all NAP cell scans. For survey/detailed scans $E_{\text {pass }}$ of $60 / 20 \mathrm{eV}$ were used.

In order to anneal samples in $\mathrm{NH}_{3}, \mathrm{CK}$ Gas Ammonia N3.8 (c.99.98 \%) was run through the NAP cell and maintained at an in-situ cell pressure $\sim 0.60 \mathrm{mbar}$ and up to $600 \mathrm{~K}$ for $20 \mathrm{mins}$. The samples were then cooled to $400 \mathrm{~K}$ before removing the $\mathrm{NH}_{3}$. Heating was applied using electron bombardment by an e-beam heater (EBH-150). The emission current was increased from $1.00 \mathrm{~mA}$ to a maximum of $30.00 \mathrm{~mA}$ to achieve the desired temperatures. The sample temperate was measured by a thermocouple attached to the sample plate. When required oxidation and reduction treatments were performed before $\mathrm{NH}_{3}$ anneals. Oxidation of samples was achieved by heating on a hot plate in air at $200{ }^{\circ} \mathrm{C}$ for 20 mins. The presence of $\mathrm{Cu}_{2} \mathrm{O}$ post-oxidation of the sample was then confirmed by the high intensity $O$ 1s peak in the XPS at $530.4 \mathrm{eV}^{36}$ (Figure 5a). Reduction of samples was performed by heating in UHV until the $\mathrm{O} 1 \mathrm{~s}$ peak was minimised, whilst ensuring the $\mathrm{C} 1 \mathrm{~s} \mathrm{sp} \mathrm{s}^{2}$ peak remained. Samples were then annealed in $\mathrm{NH}_{3}$ as previously described.

Si transfer was performed using the PAT method. The process began by spin-coating a layer of poly(methyl methacrylate) (PMMA) at $500 \mathrm{rpm}$ for $10 \mathrm{~s}$ followed by $1000 \mathrm{rpm}$ for $60 \mathrm{~s}$. To set the PMMA, the PMMA/graphene/Cu was baked for 10 mins at $80{ }^{\circ} \mathrm{C}$. The $\mathrm{Cu}$ foil was then dissolved in $0.1 \mathrm{M}$ ammonium persulfate (APS) $\mathrm{Cu}$ etchant. Once the $\mathrm{Cu}$ underneath was etched, the PMMA/graphene stack was transferred though several deionised (DI) water baths, before being deposited on the Si target substrate. When the sample was dry the PMMA was dissolved in acetone.

Data processing was carried out using CASA XPS processing software. All peaks were calibrated to the $\mathrm{Cu} 2 \mathrm{p}_{3 / 2}$ peak at $E_{B}=932.6 \mathrm{eV}^{52}$. Although our samples' surface composition is either metallic $\mathrm{Cu}$ or a mixture of metallic $\mathrm{Cu}$ and $\mathrm{Cu}_{2} \mathrm{O}$, the chemical shift between $\mathrm{Cu}$ and $\mathrm{Cu}_{2} \mathrm{O}$ is negligibly small $(\sim 0.1 \mathrm{eV})^{53-56}$. Regions and components were fitted to each peak with the appropriate RSF. Generally a Shirley background type was used. In cases where the intensity was flat or higher at lower $E_{B}$ a Linear background type was used. A symmetric Gaussian-Lorentzian product (pseudo-Voigt) line shape was used for all but $\mathrm{Cu} 2 \mathrm{p}$ peaks, where an asymmetric Lorentzian line shape was used.

AFM measurements were carried out at room temperature using a Bruker Multimode8 SPM, operated in Quantitative NanoMechanical mode. A silicon tip on nitride Bruker lever was used (model: SCANASYST-AIR). A variety of parameters were captured using NanoScope 8.2, which were then analysed using Gwyiddion. Errors in bubble distribution were calculated using the standard error of the mean, $\sigma_{M}=\sigma / \sqrt{ } N$, where $\sigma$ is the standard deviation of the original distribution and $N$ is the sample size. $\mathrm{N}$ of 25 and 29 were analysed before and after $\mathrm{NH}_{3}$ treated samples, respectively.

Raman spectra were taken using a Renishaw inVia Raman microscope with a $532 \mathrm{~nm}$ laser. The beam was focused using a $20 \times$ objective lens, laser power of $3.32 \mathrm{~mW}$ and a grating of $1800 \mathrm{l} / \mathrm{mm}$. For the un-transferred samples (i.e. on $\mathrm{Cu}$ substrate), a Raman map over the entire sample $(1 \times 1 \mathrm{~cm} 2)$ was taken with a $31 \times 31$ grid. The photoluminescent background caused by the $\mathrm{Cu}$ substrate was subtracted as described in the ESI (Figure S2-3) ${ }^{57}$. These data were then imported into OriginPro and the $G$ and $2 D$ peaks were fitted with Lorentzian peaks to determine their FWHM.

\section{Conclusions}

In conclusion, we have demonstrated a novel route to intercalating $\mathrm{N}_{2}$ and producing GNBs under CVD graphene grown on $\mathrm{Cu}$ by a simple substrate oxidation followed by $\mathrm{NH}_{3}$ annealing. Through a combination of NAP-XPS, Raman spectroscopy and AFM, we reveal that $\mathrm{NH}_{3}$ intercalates under the graphene and is subsequently decomposed by the $\mathrm{Cu}$ oxide to produce molecular nitrogen which is then entrapped, coexisting in two species: a uniform layer of $\mathrm{N}_{2}$ intercalated between the graphene/Cu layer and GNB formation.

The results demonstrated here show that graphene can be used to confine molecular reactions, the products of which open up the possibility of studying unique material properties. We have demonstrated that transfer is nonessential and GNBs may be produced through reactions with the growth substrate making it easily integrated into the conventional CVD process. These reactions could be studied prior to transfer, in-situ, in systems such as XPS, AFM or environmental scanning electron microscopy (ESEM). Given that the bubbles persist in atmospheric conditions (ESI, Figure S1) the same sample may in fact be studied in various systems prior to their collapse or transfer. Though outside the scope of this paper we anticipate this approach can be generalized and extended to graphene on other catalytic substrates (e.g. Pt, Ni, Ir, Ru) where graphene has been grown directly or transferred. Similarly, graphene may then be used to confine molecular reactions, specific to the desired substrate, where large, unreactive molecules are produced from smaller reactive ones (e.g oxidation of $\mathrm{CO}$ to $\mathrm{CO}_{2}$ - as $\mathrm{CO}$ is known to intercalate intact under graphene ${ }^{41,43,58}$ ) offering up the possibility of tailoring GNBs with different gases or gas mixtures for particular applications.

\section{Conflicts of interest}

There are no conflicts to declare.

\section{Acknowledgements}

KMZ thanks the EPSRC for provision of a studentship. ASW acknowledges funding from the EPSRC (EP/S004335/1). NearAmbient Pressure XPS access was supported by the Henry Royce Institute for Advanced Materials, funded through EPSRC grants $\mathrm{EP} / \mathrm{R00661X/1}$ and EP/P025021/1.

\section{References}

$1 \quad$ K. S. Novoselov, A. K. Geim, S. V. Morozov, D. Jiang, Y. Zhang, S. V. Dubonos, I. V. Grigorieva and A. A. Firsov, 
Electric Field Effect in Atomically Thin Carbon Films, Science, 2004, 306, 666-669.

C. Lee, X. Wei, J. W. Kysar and J. Hone, Measurement of the elastic properties and intrinsic strength of monolayer graphene, Science, 2008, 321, 385-388. J. S. Bunch, S. S. Verbridge, J. S. Alden, A. M. Van Der Zande, J. M. Parpia, H. G. Craighead and P. L. Mceuen, Impermeable Atomic Membranes from Graphene Sheets, Nano Lett., 2008, 8, 2458-2462. K. Yue, W. Gao, R. Huang and K. M. Liechti, Analytical methods for the mechanics of graphene bubbles, J. Appl. Phys., 2012, 112, 083512-8. P. Wang, W. Gao, Z. Cao, K. M. Liechti and R. Huang, Numerical Analysis of Circular Graphene Bubbles, J. Appl. Mech., 2013, 80, 040905-9.

E. Khestanova, F. Guinea, L. Fumagalli, A. K. Geim and I. V. Grigorieva, Universal shape and van der Waals pressure, Nat. Commun., 2016, 7, 12587-10. G. Wang, Z. Dai, Y. Wang, P. Tan, L. Liu, Z. Xu, Y. Wei, R. Huang and Z. Zhang, Measuring Interlayer Shear Stress in Bilayer Graphene, Phys. Rev. Lett., 2017, 119, 036101-7. K. S. Vasu, E. Prestat, J. Abraham, J. DIx, R. J. Kashtiban, J. Beheshtian, J. Sloan, P. Carbone, M. Neek-Amal, S. J. Haigh, A. K. Geim and R. R. Nair, Van der Waals pressure and its effect on trapped interlayer molecules, Nat. Commun., 2016, 7, 12168-12173. E. lakovlev, P. Zhilyaev and I. Akhatov, Atomistic study of the solid state inside graphene nanobubbles, Sci. Rep., 2017, 7, 17906-17973.

10 E. Stolyarova, D. Stolyarov, K. Bolotin, S. Ryu, L. Liu, K. T. Rim, M. Klima, M. Hybertsen, I. Pogorelsky, I. Pavlishin, K. Kusche, J. Hone, P. Kim, H. L. Stormer, O. V. Yakimenko and G. Flynn, Observation of Graphene Bubbles and Effective Mass Transport under Graphene Films, Nano Lett., 2008, 9, 332-337.

11 T. Georgiou, L. Britnell, P. Blake, R. V. Gorbachev, A. Gholinia, A. K. Geim, C. Casiraghi and K. S. Novoselov, Graphene bubbles with controllable curvature, Appl. Phys. Lett., 2011, 99, 93103-3.

12 A. V. Kretinin, Y. Cao, J. S. Tu, G. L. Yu, R. Jalil, K. S. Novoselov, S. J. Haigh, A. Gholinia, A. Mishchenko, M. Lozada, T. Georgiou, C. R. Woods, F. Withers, P. Blake, G. Eda, A. Wirsig, C. Hucho, K. Watanabe, T. Taniguchi, A. K. Geim and R. V. Gorbachev, Electronic Properties of Graphene Encapsulated with Different Two-Dimensional Atomic Crystals, Nano Lett., 2014, 14, 3270-3276.

13 Z. Zong, C.-L. Chen, M. R. Dokmeci and K.-T. Wan, Direct measurement of graphene adhesion on silicon surface by intercalation of nanoparticles, J. Appl. Phys., 2010, 107, 026104-3.

14 J. Zabel, R. R. Nair, A. Ott, T. Georgiou, A. K. Geim, K. S. Novoselov and C. Casiraghi, Raman spectroscopy of graphene and bilayer under biaxial strain: Bubbles and balloons, Nano Lett., 2012, 12, 617-621.

15 N. Levy, S. A. Burke, K. L. Meaker, M. Pamlasigui, A. Zettl, G. Guinea, A. H. Castro Neto and M. F. Crommie, StrainInduced Pseudo-Magnetic Fields Greater Than 300 Tesla in
Graphene Nanobubbles, Science, 2010, 329, 544-547. Q. Bao, J. Chen, Y. Xiang, K. Zhang, S. Li, X. Jiang, Q. H. Xu, K. P. Loh and T. Venkatesan, Graphene Nanobubbles: A New Optical Nonlinear Material, Adv. Opt. Mater., 2015, 3, 744-749.

Y. Wang, Y. Zheng, X. Xu, E. Dubuisson, Q. Bao, J. Lu and K. $P$. Loh, Electrochemical delamination of CVD-grown graphene film: Toward the recyclable use of copper catalyst, ACS Nano, 2011, 5, 9927-9933. L. Gao, W. Ren, H. Xu, L. Jin, Z. Wang, T. Ma, L.-P. Ma, Z. Zhang, Q. Fu, L.-M. Peng, X. Bao and H.-M. Cheng, Repeated growth and bubbling transfer of graphene with millimetre-size single-crystal grains using platinum, Nat. Commun., 2012, 3, 699-7.

19 H. An, B. H. Tan, J. G. S. Moo, S. Liu, M. Pumera and C. D. Ohl, Graphene Nanobubbles Produced by Water Splitting, Nano Lett., 2017, 17, 2833-2838.

F. Guinea, Strain engineering in graphene, Solid State Commun., 2012, 152, 1437-1441.

C. Zhao, J. Li, J. Dai, E. Voloshina, Y. Dedkov and Y. Cui, Intercalation of $\mathrm{O} 2$ and $\mathrm{N} 2$ in the Graphene/Ni Interfaces of Different Morphologies, J. Phys. Chem. C, 2019, 123, 16137-16145.

N. M. Caffrey, R. Armiento, R. Yakimova and I. A. Abrikosov, Charge neutrality in epitaxial graphene on $6 \mathrm{H}$ $\mathrm{SiC}(0001)$ via nitrogen intercalation, Phys. Rev. B - Condens. Matter Mater. Phys., 2015, 92, 81409-5.

Z. jun Wang, M. Wei, L. Jin, Y. Ning, L. Yu, Q. Fu and X. Bao, Simultaneous $\mathrm{N}$-intercalation and $\mathrm{N}$-doping of epitaxial graphene on $6 \mathrm{H}-\mathrm{SiC}(0001)$ through thermal reactions with ammonia, Nano Res., 2013, 6, 399-408. H. C. Choi, S. Y. Bae, J. Park, K. Seo and C. Kim, Experimental and theoretical studies on the structure of $\mathrm{N}$ doped carbon nanotubes: Possibility of intercalated molecular N2, App. Phys. Lett., 2004, 85, 5742-5744. J. D. Wiggins-Camacho and K. J. Stevenson, Effect of Nitrogen Concentration on Capacitance, Density of States, Electronic Conductivity, and Morphology of N-Doped Carbon Nanotube Electrodes, J. Phys. Chem. C, 2009, 113, 19082-19090.

P. Ayala, A. Grüneis, T. Gemming, D. Grimm, C. Kramberger, M. H. Rümmeli, F. L. Freire, H. Kuzmany, R. Pfeiffer, A. Barreiro, B. Büchner and T. Pichler, Tailoring Ndoped Single and Double Wall Carbon Nanotubes from a Nondiluted Carbon/ Nitrogen Feedstock, J. Phys. Chem. C, 2007, 111, 2879-2884.

H. C. Choi, J. Park and B. Kim, Distribution and Structure of N Atoms in Multiwalled Carbon Nanotubes Using VariableEnergy X-Ray Photoelectron Spectroscopy, J. Phys. Chem. B., 2005, 109, 4333-4340. H. Tillborg, A. Nilsson, B. Hernnäs, N. Mårtensson and R. E. Palmer, X-ray and UV photoemission studies of mono-, biand multilayers of physisorbed molecules: $\mathrm{O} 2$ and N2 on graphite, Surf. Sci. Lett., 1993, 295, 1-12. E. N. Voloshina, A. Generalov, M. Weser, S. Böttcher, K. Horn and Y. S. Dedkov, Structural and electronic properties of the graphene/Al/Ni(111) intercalation system, New J. 
Phys., 2011, 13, 113028-113046.

30 H. Wang, T. Maiyalagan and X. Wang, Review on recent progress in nitrogen-doped graphene: Synthesis, characterization, and its potential applications, ACS Catal., 2012, 2, 781-794.

31 G. Soto, J. A. Díaz and W. De La Cruz, Copper nitride films produced by reactive pulsed laser deposition, Mater. Lett., 2003, 57, 4130-4133.

32 A. P. Baddorf and D. M. Zehner, Chemisorption of nitrogen on $\mathrm{Cu}(110)$ : coverage and site determination, Surf. Sci., 1990, 238, 255-263.

33 R. Spitzl, H. Niehus and G. Comsa, Structure investigation of the nitrogen induced $\mathrm{Cu}(110)-(2 \times 3)$ phase with $180^{\circ}$ low energy impact collision ion scattering spectroscopy, Surf. Sci. Lett., 1991, 250, L335-L362.

34 B. Afsin, P. R. Davies, A. Pashusky, M. W. Roberts and D. Vincent, Reaction pathways in the oxydehydrogenation of ammonia at $\mathrm{Cu}(110)$ surfaces, Surf. Sci., 1993, 284, 109120.

35 T. Sueyoshi, T. Sasaki and Y. Iwasawa, Coadsorption of NO and $\mathrm{NH} 3$ on $\mathrm{Cu}(111)$ : The formation of the stabilized $(2 \times 2)$ coadlayer, J. Phys. Chem., 1996, 100, 13646-13654.

36 J. Li, Z. Mei, L. Liu, H. Liang, A. Azarov, A. Kuznetsov, Y. Liu, A. Ji, Q. Meng and X. Du, Probing Defects in NitrogenDoped Cu2O, Sci. Rep., 2014, 4, 7240-6.

37 S. Hinokuma, S. Matsuki, Y. Kawabata, H. Shimanoe, S. Kiritoshi and M. Machida, Copper Oxides Supported on Aluminum Oxide Borates for Catalytic Ammonia Combustion, J. Phys. Chem. C, 2016, 120, 24734-24742. M. A. Henderson, The interaction of water with solid surfaces: fundamental aspects revisited, Surf. Sci. Rep., 2002, 46, 1-308.

39 G. Ketteler, S. Yamamoto, H. Bluhm, K. Andersson, D. E. Starr, D. F. Ogletree, H. Ogasawara, A. Nilsson and M. Salmeron, The nature of water nucleation sites on TiO2(110) surfaces revealed by ambient pressure X-ray photoelectron spectroscopy, J. Phys. Chem. C, 2007, 111, 8278-8282.

40 M. J. Jackman, A. G. Thomas and C. Muryn, Photoelectron spectroscopy study of stoichiometric and reduced anatase TiO<inf $>2</$ inf $>(101)$ surfaces: The effect of subsurface defects on water adsorption at near-ambient pressures, $J$. Phys. Chem. C, 2015, 119, 13682-13690.

41 E. Graišnäs, M. Andersen, M. A. Arman, T. Gerber, B. Hammer, J. Schnadt, J. N. Andersen, T. Michely and J. Knudsen, $\mathrm{CO}$ intercalation of graphene on $\operatorname{Ir}(111)$ in the millibar regime, J. Phys. Chem. C, 2013, 117, 16438-16447. P. Sutter, J. T. Sadowski and E. A. Sutter, Chemistry under cover: Tuning metal-graphene interaction by reactive intercalation, J. Am. Chem. Soc., 2010, 132, 8175-8179. R. Mu, Q. Fu, L. Jin, L. Yu, G. Fang, D. Tan and X. Bao, Visualizing Chemical Reactions Confined under Graphene, Angew. Chem. Int. Ed., 2012, 51, 4856-4859.
Z. Xu and M. J. Buehler, Interface structure and mechanics between graphene and metal substrates: A first-principles study, J. Phys. Condens. Matter, 2010, 22, 485301-5. D. W. Breck, Zeolite molecular sieves: structure, chemistry, and use, John Wiley \& Sons Inc, New York, 1974. $\mathrm{X}$. Feng, S. Maier and M. Salmeron, Water splits epitaxial graphene and intercalates, J. Am. Chem. Soc., 2012, 134, 5662-5668.

K. Wong, S. J. Kang, C. W. Bielawski, R. S. Ruoff and S. K. Kwak, First-Principles Study of the Role of $\mathrm{O} 2$ and $\mathrm{H} 2 \mathrm{O}$ in the Decoupling of Graphene on $\mathrm{Cu}(111)$, J. Am. Chem. Soc., 2016, 138, 10986-10994.

S. Blankenburg, M. Bieri, R. Fasel, K. Müllen, C. A. Pignedoli and $\mathrm{D}$. Passerone, Porous graphene as an atmospheric nanofilter, Small, 2010, 6, 2266-2271.

J. S. Lim and G. Kim, First-principles modeling of water permeation through periodically porous graphene derivatives, J. Colloid Interface Sci., 2019, 538, 367-376. R. Ramírez-Jíménez, L. Álvarez-Fraga, F. Jimenez-Villacorta, E. Climent-Pascual, C. Prieto and A. de Andrés, Interference enhanced Raman effect in graphene bubbles, Carbon N. Y., 2016, 105, 556-565.

A. Eckmann, A. Felten, I. Verzhbitskiy, R. Davey and C. Casiraghi, Raman study on defective graphene: Effect of the excitation energy, type, and amount of defects, Phys. Rev. B - Condens. Matter Mater. Phys., 2013, 88, $035426-$ 11.

M. P. Seah, I. S. Gilmore and G. Beamson, XPS: Binding Energy Calibration of Electron Spectrometers 5-Reevaluation of the Reference Energies, Surf. Interface Anal., 1998, 26, 642-649.

G. Panzner, B. Egert and H. P. Schmidt, The Stability of CuO and Cu2O Surfaces During Argon Sputtering Studied by XPS and AES, Surf. Sci., 1984, 151, 400-408.

P. E. Larson, $\mathrm{X}$-ray induced photoelectron and auger spectra of $\mathrm{Cu}, \mathrm{CuO}, \mathrm{Cu} 2 \mathrm{O}$, and $\mathrm{Cu} 2 \mathrm{~S}$ thin films, J. Electron Spectros. Relat. Phenomena, 1974, 4, 213-218.

J. P. Espinós, J. Morales, A. Barranco, A. Caballero, J. P. Holgado and A. R. González-Elipe, Interface effects for $\mathrm{Cu}$, $\mathrm{CuO}$, and $\mathrm{Cu} 2 \mathrm{O}$ deposited on $\mathrm{SiO} 2$ and $\mathrm{ZrO} 2$. XPS determination of the valence state of copper in $\mathrm{Cu} / \mathrm{SiO} 2$ and Cu/ZrO 2 catalysts, J. Phys. Chem. B, 2002, 106, 69216929.

M. C. Biesinger, L. W. M. Lau, A. R. Gerson and R. S. C. Smart, Resolving surface chemical states in XPS analysis of first row transition metals, oxides and hydroxides: $\mathrm{Cr}, \mathrm{Mn}$, $\mathrm{Fe}, \mathrm{Co}$ and Ni, Appl. Surf. Sci., 2010, 257, 887-898. S. D. Costa, A. Righi, C. Fantini, Y. Hao, C. Magnuson, L. Colombo, R. S. Ruoff and M. A. Pimenta, Resonant Raman spectroscopy of graphene grown on copper substrates, Solid State Commun., 2012, 152, 1317-1320. T. Li and J. A. Yarmoff, The orientation of CO intercalated between graphene and Ru(0001), Surf. Sci., 2019, 680, 610. 